\title{
Development of Gastrointestinal Mucosal Barrier. I. The Effect of Age on Intestinal Permeability to Macromolecules
}

\author{
J. N. UDALL, \\ Department of Pediatrics. Harvard Medical School, the Children's Service (Pediatric Gastrointestinal and Nutrition \\ Unit), Massachusetts General Hospital, Boston, Massachusetts and the Department of Nutrition and Food Science. \\ Massachusetts Institute of Technologi. Cambridge, Massachusetts, USA
}

\begin{abstract}
Summary
Indirect evidence has suggested that increased quantities of antigen may penetrate the intestinal mucosa and enter the systemic circulation during the newborn period compared to adult life. However, no direct measurement of macromolecular transport has been reported as a function of perinatal age. To study this process, we administered $100 \mathrm{mg}$ of tritiated bovine serum albumin $\left({ }^{3} \mathrm{H} \mid \mathrm{BSA}\right)$ by gavage to rabbits at birth, one wk, $2 \mathrm{wk}, 6 \mathrm{wk}$, and one year of age and measured plasma radioactivity $4 \mathrm{hr}$ after gavage. Plasma concentration of trichloroacetic acid insoluble radioactivity and immunoreactive bovine serum albumin radioactivity decreased significantly after one wk of age. When adult animals were gavaged with the same amount of $\left.\right|^{3} \mathrm{H} \mid \mathrm{BSA}$ per body weight as the one-wk-old animals, they failed to transport as much of the antigen as the younger animals. This study, therefore, provides objective evidence that the intestinal mucosal barrier of newborns may be incompletely developed at birth and allow increased intestinal transport of antigens into the circulation.
\end{abstract}

\section{Speculation}

The development of an animal model for the study of gastrointestinal host defense during the neonatal period may ultimately provide the basis for a better understanding of the mechanisms responsible for intestinal uptake of antigenic molecules and their contribution, if any, to the pathogenesis of human disease. Of particular importance is the accurate quantitation of immunologically reactive antigen absorbed by newborn animals. Using immunologic techniques to quantitate macromolecular transport, it can be determined whether conditions (enteric delivery of nutrients, growth factors in natural milk, etc.) thought to stimulate intestinal epithelial cell turnover can also accelerate the development of the intestinal mucosal barrier and thereby contribute to the protection of the infant from potentially harmful luminal antigens.

Intestinal absorption of intact macromolecules is alleged to be maximal in the newborn period and decrease with age, presumably because of the maturation of the intestinal mucosal barrier (14) However, this hypothesis is based on fragmentary data obtained from studies in a variety of animal models and utilizing a number of biologically different macromolecules. Most macromolecular transport studies in newborns have been directed toward defining the mechanism of transport of intact immunoglobulins in animals receiving partial (rats) or complete passive immunity postnatally (sheep and pigs) and have been concerned with factors contributing to cessation of this unique perinatal transport process (closure). In contrast to the well-studied transport of immunoglobulins in newborn animals such as the rat $(7,8)$, few studies have been done to specifically investigate transintestinal transport of non- immunoglobulin macromolecules in young animals receiving complete intrauterine passive immunity (rabbits and humans).

Therefore, the present study was undertaken to determine if the intestinal transport of the nonimmunoglobulin protein, bovine serum albumin (BSA), a common food antigen, could be quantitated in newborn rabbits and compared to its transport in older animals.

\section{MATERIALS AND METHODS}

\section{ANIMALS}

Adult New Zealand White does (Margaret's Home Farm, Greenfield, MA) were raised on Charles River Rabbit Chow (Country Foods, Syracuse, NY), a plant protein-based diet which contains no BSA. Does were mated, and on the 31 st day of a 31 day gestation, labor was induced by the intramuscular injection of 1.0 U.S.P. unit of oxytocin (Sandoz Pharmaceuticals, East Hanover, NJ), diluted to $0.2 \mathrm{ml}$ with distilled water. The mean birth weight was $49.0 \pm 3.0 \mathrm{~g}(\overline{\mathrm{x}} \pm$ S.E. $)$ for 25 newborn rabbits studied. Infant rabbits which weighed less than $40 \mathrm{~g}$ at birth were considered low-birthweight animals and were not used in experiments.

Newborn rabbits were either studied at birth before suckling could occur or allowed to remain with the mother and suckle ad lib for 1,2 , or $6 \mathrm{wk}$. They attained mean weights of $101.0 \pm 9.0$, $230.0 \pm 16.0$, and $942.0 \pm 53.0 \mathrm{~g}$ during these respective intervals. Ten naturally raised one-year-old adult animals weighing 4.580 $\pm 180 \mathrm{~g}$ were also studied. Plasma volume of animals at each age was calculated according to previous standards (9).

\section{TRANSPORT STUDIES}

Lyophilized crystalline BSA (Sigma Chemical Co., St. Louis, MO) was radiolabeled (New England Nuclear, Boston, MA) with tritium using the Wilzbach method (16). [ $\left.{ }^{3} \mathrm{H}\right] \mathrm{BSA}$ was then dialyzed against phosphate-buffered saline (PBS) (0.15 M NaCl-6.7 $\mathrm{mM} \mathrm{NaH} 2 \mathrm{PO}_{4}-1.7 \mathrm{mM} \mathrm{Na} \mathrm{HPO}_{4}, \mathrm{pH} 7.4$ ) solution and concentrated using a minicon concentrator (Amicon Corp., Lexington, MA). When dialyzed specimens were fractionated using a Bio-Gel P-60 (Biorad, Richmond, CA) column, $90 \%$ of the counts eluted in the void volume fractions (molecular weight $>60,000$ daltons). A trace amount of the dialyzed $\left[{ }^{3} \mathrm{H}\right] \mathrm{BSA}$ was added to $100 \mathrm{mg}$ BSA per ml PBS solution to attain a specific activity of approximately $3.0 \times 10^{4} \mathrm{cpm} / \mathrm{mg}$ BSA. In routine experiments, each animal was given $100 \mathrm{mg}$ of $\left[{ }^{3} \mathrm{H}\right] \mathrm{BSA}$ in $1 \mathrm{ml}$ PBS. Newborn rabbit growth data indicate that the $100 \mathrm{mg}$ of protein administered by gavage probably represents a physiologic amount of protein. This is based on the observation that newborn rabbits feeding once a day will suckle at least 8 to $10 \mathrm{~g}$ of milk (18) which is $11.0 \%$ protein $(2)$. Therefore, naturally raised infant rabbits will ingest approximately $1.0 \mathrm{~g}$ of protein at a feeding. 
All animals were fasted overnight before being studied except for animals at birth who were kept in the fasted state for a minimum of $3 \mathrm{hr}$ in a 30 to $32^{\circ} \mathrm{C}$ incubator. Each animal was then given the $100 \mathrm{mg}$ of $\left[{ }^{3} \mathrm{H}\right] \mathrm{BS} A$ through a polyethylene tube (Intramedic, Parsippany, NJ) by oral-gastric infusion. Animals were anesthetized with ether and heparinized blood was obtained by cardiac puncture. In animals at birth, blood was obtained at 1 , $2,4,8$, or $12 \mathrm{hr}$ after $\left[{ }^{3} \mathrm{H}\right] \mathrm{BSA}$ gavage to determine plasma radioactivity. Whole blood was cleared of red blood cells by centrifugation, and aliquots of plasma samples were analyzed for protein-bound (TCA insoluble) or immunoreactive BSA (I-BSA) radioactivity. Plasma radioactivity was observed to be greatest at $4 \mathrm{hr}$ after [ $\left.{ }^{3} \mathrm{H}\right] \mathrm{BSA}$ gavage in the animals at birth. Therefore, older animals $(1,2,6$, and $52 \mathrm{wk})$ were all sampled at $4 \mathrm{hr}$ and plasma radioactivity was compared to newborn radioactivity.

In two additional experiments, one-year-old animals were gavaged with $5.0 \mathrm{~g}$ of $\left[{ }^{3} \mathrm{H}\right] \mathrm{BSA}$ (specific activity of approximately $\left.7.0 \times 10^{3} \mathrm{cpm} / \mathrm{mg} \mathrm{BSA}\right)$ in $50 \mathrm{ml}$ of PBS (100 mg BSA per $\left.\mathrm{ml}\right)$ and heparinized blood was obtained from an ear vein $1,2,4,8$, 12 , and $24 \mathrm{hr}$ later for TCA insoluble and I-BSA radioactivity determination.

\section{QUANTITATION OF CIRCULATORY MACROMOLECULES}

Two methods of quantitating macromolecular transport from the intestinal lumen to the blood were used. Plasma samples were examined using a standard isotope method, which has been widely used for macromolecular transport studies, and an immunologic method.

Isotope Method. Plasma samples (50 to $500 \mu \mathrm{l}$ ) were counted in $10.0 \mathrm{ml}$ of Aquasol scintillation fluid (New England Nuclear, Boston, MA) using a liquid scintillation counter (Delta 300; Searle, Chicago, IL). TCA radioactivity was determined by precipitating plasma proteins with $10 \%$ TCA (10) and determining supernatant radioactivity. Total supernatant radioactivity was subtracted from total plasma radioactivity to obtain TCA-insoluble radioactivity. This indirect method of assessing TCA-insoluble radioactivity has been used by others (4) and avoids the difficulty of neutralizing the chemiluminescence generated by solubilizing the TCA precipitate to determine its radioactivity.

Immunoreactive BSA Method. Concentration of circulating IBSA was determined in each sample obtained. All plasma samples were first cleared of lipid by centrifugation at 13,000 rpm for 30 min then examined using electroimmunodiffusion (5). Rabbit anti-BSA (Miles Laboratories, Elkhart, IN; Cappel Laboratories, Cochranville, PA) was mixed with a $1 \%$ agarose gel. Known quantities of BSA mixed with rabbit plasma were run simultaneously with samples as standards. Based on a standard curve relating electrophoretic migration to BSA concentration, the IBSA content of unknown plasma samples was quantitated. The lower limit of sensitivity of this method was $1.0 \mu \mathrm{g}$ I-BSA per ml plasma. Plasma I-BSA was expressed as radioactivity to compare it with insoluble radioactivity obtained by the isotope method. The I-BSA radioactivity was calculated by multiplying the I-BSA per $\mathrm{ml}$ in the plasma of animals gavaged with [ $\left.{ }^{3} \mathrm{H}\right] \mathrm{BSA}$ by the specific activity of the original $\left[{ }^{3} \mathrm{H}\right] \mathrm{BSA}$ in the gavage fluid.

Immunoreactive bovine serum albumin measured by electroimmunodiffusion (EID) initially appeared to represent intact BSA and not polypeptide antigenic determinants because plasma samples examined by two-dimensional immunoelectrophoresis (15) showed only one peak. To assure that EID measured only the intact and antigenically active bovine serum albumin, experiments were performed to determine if BSA fragments were detected by the electroimmunodiffusion assay. Lyophilized and crystalline BSA was digested with pepsin and trypsin according to Wright and Rothberg (17). The resulting preparation was then fractionated on a Sephacryl 300 (Pharmacia Fine Chemicals, Piscataway, $\mathrm{NJ})$ column $(2.5 \times 85 \mathrm{~cm})$ using a Tris buffer $(10 \mathrm{mM}$ Tris-HCl$0.123 \mathrm{M} \mathrm{NaCl}-5.0 \mathrm{mM} \mathrm{CaCl}{ }_{2} \cdot 2 \mathrm{H}_{2} \mathrm{O} \mathrm{pH} 7.5$ ). A Varioperpex II pump (LKB, Stockholm, Sweden) generating a flow rate of 0.5 $\mathrm{ml} / \mathrm{min}$ was used to collect one hundred twenty $6.0 \mathrm{ml}$ fractions.
Approximate intervals of every 17 tubes were pooled from the highest molecular weight to the lowest. The pooled fractions had protein concentrations in the range of 0.1 to $1.0 \mathrm{mg} / \mathrm{ml}$. BSA fragments from each of the pools did not form "precipitation rockets" on EID. However, when BSA was added to an aliquot of each pooled fraction to give a final concentration of $20 \mu \mathrm{g}$ BSA per $\mathrm{ml}$, an increase in "rocket heights" relative to a $20 \mu \mathrm{g}$ BSA per $\mathrm{ml}$ standard was noted with the higher molecular weight fragments. This spuriously high EID value for BSA concentration suggests that nonprecipitating BSA breakdown fragments which retain antigenic determinants partially interfere with the EID assay. The presence of nonprecipitating but antigenically active breakdown products interfering with an immunoassay has been noted by others (1).

In addition, experiments were performed to determine if BSA fragments could be detected by EID in the plasma of animals fed $\left[{ }^{3} \mathrm{H}\right] \mathrm{BSA}$. Using antiserum to BSA fragments prepared by inoculating male rabbits subcutaneously with $15.0 \mathrm{mg}$ of pepsin-digested BSA (17) in complete Freund's adjuvant, we were unable to demonstrate the presence of fragments by EID in blood obtained from the heart or peripheral veins of rabbits gavaged with $\left[{ }^{3} \mathrm{H}\right]$ BSA. Therefore, it is unlikely that large amounts of BSA fragments are circulating in plasma after [ $\left.{ }^{3} \mathrm{H}\right] \mathrm{BSA}$ gavage. It is possible, however, that very small amounts of antigenically active BSA fragments not detected by our anti-fragment antiserum may be influencing the EID assay. For this reason, it must be stated that the EID assay used in this system measures antigenically intact BSA and antigenically active BSA fragments, both considered to be macromolecules.

To control for the possibility that circulating antibodies to BSA in older rabbits might interfere with the measurement of I-BSA and thus contribute to erroneously lowered plasma levels of IBSA, counterelectrophoresis (3) was performed using plasma from selected naturally raised rabbits at each age. No anti-BSA activity was detected in the plasma samples from any of the rabbits using this technique. This observation confirmed that rabbits had not been sufficiently exposed to BSA to develop circulating antibodies.

Statistics. All determinations of statistical significance were made utilizing Student's $t$ test.

\section{RESULTS}

\section{NEWBORN TRANSPORT STUDIES}

In rabbits studied immediately after birth, I-BSA increased with time after oral-gastric instillation of $\left[{ }^{3} \mathrm{H}\right] \mathrm{BSA}$. Figure 1 compares I-BSA per $\mathrm{ml}$ of plasma at various time points up to $12 \mathrm{hr}$ after antigen infusion. Immunoreactive BSA was undetectable at one hour, $0.88 \pm 0.88 \mu \mathrm{g} / \mathrm{ml}(\overline{\mathrm{x}} \pm \mathrm{S}$.E. $)$ by $2 \mathrm{hr}$, and increased to 5.56

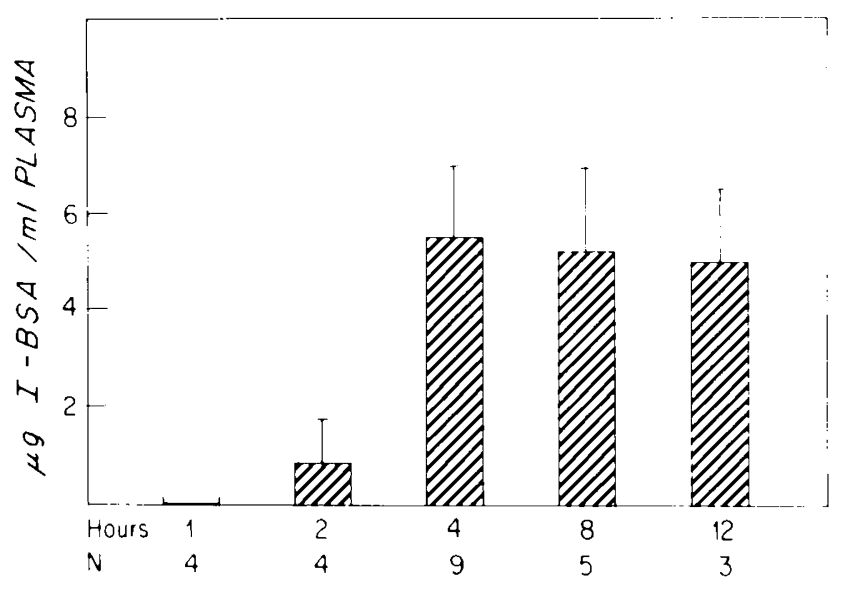

Fig. I. Immunoreactive BSA $(\mu \mathrm{g} / \mathrm{ml})$ in plasma obtained from newborn rabbits at various intervals after gavage feeding $100 \mathrm{mg}\left[{ }^{3} \mathrm{H}\right] \mathrm{BSA}(3.0$ x $10^{4} \mathrm{cpm} / \mathrm{mg} \mathrm{BSA}$ ). 
$\pm 1.49 \mu \mathrm{g} / \mathrm{ml}$ by $4 \mathrm{hr}$. There was no significant increase by either $8 \mathrm{hr}(5.24 \pm 1.73 \mu / \mathrm{ml})$ or $12 \mathrm{hr}(5.06 \pm 1.46 \mu \mathrm{g} / \mathrm{ml})$. Based on these observations, $4 \mathrm{hr}$ was selected as the time interval for plasma sampling in subsequent comparison studies.

\section{TRANSPORT STUDIES WITH AGE}

The same dose of oral $\left[{ }^{3} \mathrm{H}\right] \mathrm{BSA}$ as that given to newborn animals was given to groups of animals at $1,2,6$ wk and 1 year after birth and transport was quantitated by measuring TCAinsoluble and immunoreactive BSA radioactivity in plasma samples of animals at all ages. In the groups beyond one wk of age, a progressive decrease in radioactivity was noted as a function of age (Table 1). However, mean TCA-insoluble plasma radioactivity increased significantly $(P<0.05)$ by 1 wk after birth $(9132.0 \pm$ $1465.0 \mathrm{cpm} / \mathrm{ml})$ compared to the newborn period $(4724.0 \pm 979.0$ $\mathrm{cpm} / \mathrm{ml}$ ). By two wk of age, plasma TCA-insoluble radioactivity had decreased significantly $(2276.0 \pm 158.0 \mathrm{cpm} / \mathrm{ml} ; P<0.05)$ and continued to decrease between 2 and 6 wk $(745.0 \pm 150.0$

Table 1. Plasma BSA radioactivity determined by isotope and

\begin{tabular}{lcc}
\multicolumn{3}{c}{$I-B S A$ methods } \\
Age & $\begin{array}{c}\text { Plasma } \\
\text { TCA-insoluble } \\
\text { radioactivity' } \\
\text { (cpm/ml) }\end{array}$ & $\begin{array}{c}\text { Plasma I-BSA } \\
\text { radioactivity } \\
\text { (cpm/ml) }\end{array}$ \\
\hline Birth & 4724.0 & 167.0 \\
I wk & 9132.0 & 188.0 \\
$2 \mathrm{wk}$ & 2276.0 & 16.0 \\
$6 \mathrm{wk}$ & 745.0 & 6.0 \\
I year & 360.0 & 0 \\
\hline
\end{tabular}

' Radioactivity determined by $10 \%$ TCA precipitation of 50 to $500 \mu \mathrm{l}$ plasma obtained $4 \mathrm{hr}$ after gavage of $100 \mathrm{mg}$ of $\left[{ }^{3} \mathrm{H}\right] \mathrm{BSA}\left(3.0 \times 10^{\mathrm{ti}} \mathrm{cpm} /\right.$ $\mathrm{ml})$.

"Immunoreactive radioactivity determined by E.I.D. precipitation of $5.0 \mu \mathrm{l}$ of plasma obtained $4 \mathrm{hr}$ after gavage of $100 \mathrm{mg}$ of ["H)BSA $(3.0 \times$ $10^{6} \mathrm{cpm} / \mathrm{ml}$ ).

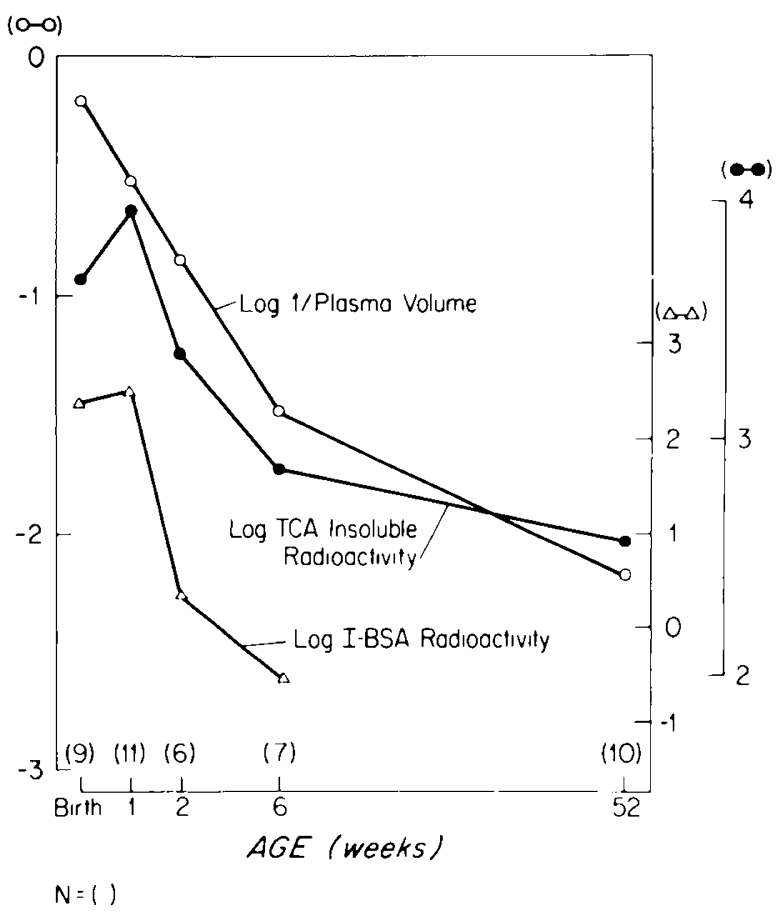

Fig. 2. The reciprocal of the mean plasma volume $(O)(1 / \mathrm{cc})$, mean TCA insoluble radioactivity $(\bullet)(\mathrm{cpm} / \mathrm{ml}$ plasma $)$, and mean immunoreactive BSA radioactivity $(\triangle)(\mathrm{cpm} / \mathrm{ml}$ plasma) are expressed as logarithms and compared at the different age intervals.

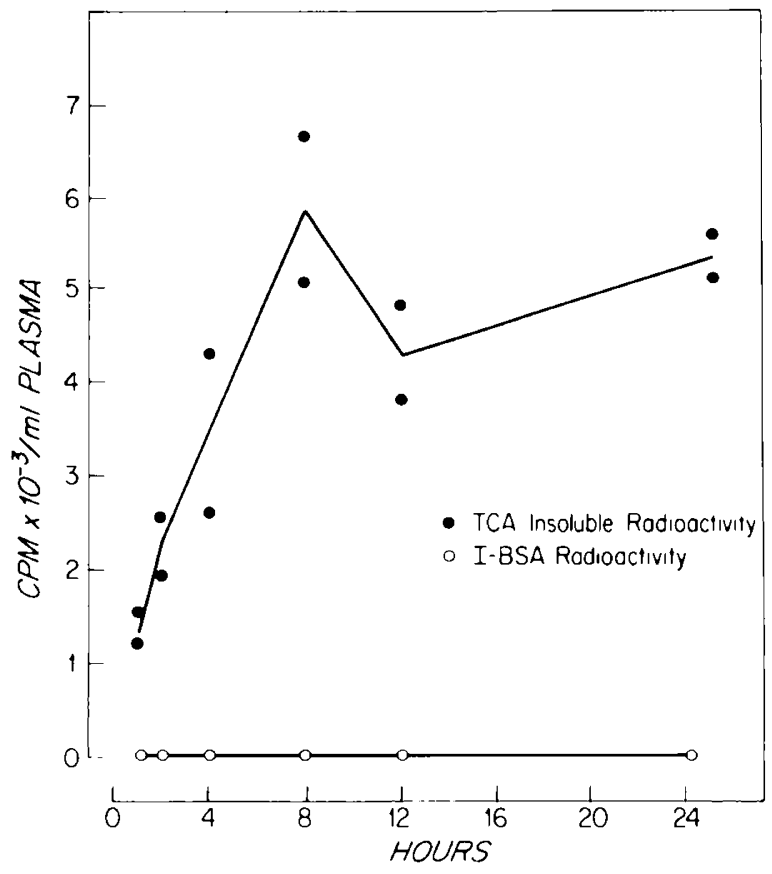

Fig. 3. Representative plasma TCA-insoluble radioactivity $(0)(\mathrm{cpm} /$ $\mathrm{ml}$ plasma), and immunoreactive BSA radioactivity $(O)(\mathrm{cpm} / \mathrm{ml}$ plasma) at various time intervals in two animals after feeding by gavage $5.0 \mathrm{~g}$ of $\left[{ }^{3} \mathrm{H}\right] \mathrm{BSA}$ in $50.0 \mathrm{ml}$ of PBS $\left(7.0 \times 10^{3} \mathrm{cpm} / \mathrm{mg} \mathrm{BSA}\right)$.

$\mathrm{cpm} / \mathrm{ml} ; P<0.01)$ and between $6 \mathrm{wk}$ and 1 year $(360.0 \pm 84.0$ $\mathrm{cpm} / \mathrm{ml} ; P<0.001$ ). In contrast I-BSA radioactivity at birth was $167.0 \pm 45.0 \mathrm{cpm} / \mathrm{ml}$. By one wk of age, mean I-BSA radioactivity had increased slightly to $188.0 \pm 22.0 \mathrm{cpm} / \mathrm{ml}$. Two-wk-old animals had significantly decreased I-BSA radioactivity $(16.0 \pm$ $10.0 \mathrm{cpm} / \mathrm{ml} ; P<0.05)$ in comparison to animals at birth, and IBSA radioactivity continued to decrease between 2 and $6 \mathrm{wk}$ of age $(6.0 \pm 6.0 \mathrm{cpm} / \mathrm{ml} ; P<0.02)$. Immunoreactive BSA was not detectable in any of the 10 adult animals studied.

To determine if increasing vascular volume with age had a dilutional effect on plasma concentration of radioactive macromolecules, concentrations of TCA and I-BSA radioactivity were compared to plasma volume. Figure 2 depicts the log of 1 /plasma volume and the mean plasma radioactivity determined by both methods in samples collected at $4 \mathrm{hr}$ at the various ages. When the log of plasma TCA-insoluble radioactivity was compared with the log of $1 /$ plasma volume, it was noted that both parameters decreased with age. The log of plasma I-BSA radioactivity also decreased with age but the log graph could not be continued beyond the 6-wk interval because no I-BSA was detected in the adult animals (Figure 2).

In Figure 3, TCA-insoluble and immunoreactive BSA radioactivity are compared in two adult animals given the same $\left[{ }^{3} \mathrm{H}\right]$ BSA dose per body weight as given the one-wk-old animals. Whereas TCA-insoluble radioactivity was detectable in timed samples over a $24-\mathrm{hr}$ period after infusion of $\left[{ }^{3} \mathrm{H}\right] \mathrm{BSA}$, no detectable I-BSA radioactivity was noted during this same period.

\section{DISCUSSION}

This study demonstrates for the first time that BSA determinants can be quantitated in plasma samples from newborns after an oral-gastric infusion of physiologic quantities of a protein antigen. It is assumed that I-BSA entered the systemic circulation after penetrating the intestinal mucosal barrier as intact antigen. The plasma concentration of this macromolecule progressively decreased with age in the animals studied until little or no circulating BSA could be detected in the plasma of adults. Even when adult rabbits were given amounts of BSA corresponding to a comparable 
dose per body weight as in one-wk-old animals, plasma immunoreactive BSA radioactivity could not be detected. These observations strongly suggest that penetration of intact proteins may be related to the maturation of the gastrointestinal mucosal barrier.

Our finding of decreased plasma radioactivity in adults given [ $\left.{ }^{3} \mathrm{H}\right] \mathrm{BSA}$ might be explained if the older animals removed antigen more rapidly from the vascular space than younger animals. To eliminate this possibility, we have noted in preliminary experiments that $25 \%$ of an intravascularly administered dose of BSA was cleared from the plasma pool of adult animals in $4 \mathrm{hr}$ compared to $30 \%$ removed from the pool of newborns. This increase in vascular permeability in newborn animals has also been noted by others (6). Therefore, the differences in serum IBSA between newborns and older animals are not the result of different rates of clearance.

Our data suggest that the quantity of macromolecules which has been transported from the intestinal lumen into the blood is overestimated by protein bound (TCA-insoluble) radioactivity when compared to radioactivity obtained by immunologic techniques (I-BSA radioactivity). This has been noted by others (12). The standard TCA precipitation method for quantitating transport of radiolabeled proteins measures not only intact BSA but may also be measuring small molecular weight radioactive fragments attached to native protein (13). EID identifies only antigenic determinants of BSA and will not be spuriously elevated by radiolabeled amino acids bound to native proteins.

Several explanations may account for the increased uptake of intestinal antigens during the newborn period. These include: (1) transient deficiency of intestinal secretory antibodies (11); (2) an increased affinity of antigens for the immature intestinal surface. i.e., increased "receptor" sites for antigens; (3) enhanced pinocytosis of macromolecules; and (4) decreased intestinal proteolysis. One or more of these factors may contribute to the enhancement of antigen uptake in the newborn rabbits. It is apparent that additional studies are needed to further clarify this observation.

\section{REFERENCES AND NOTES}

1. Andre, C.. Lamber, R., Bazin, H.. and Heremans, J. F.: Interference of oral immunization with the intestinal absorption of heterologous albumin. Eur. J. Immunol., 4: 701 (1974).

2. Cowie. A. T.: Variations in the yield and composition of the milk during lactation in the rabbit and the galactopoietic effect of prolactin. J. Endocrinol., 44: 437 (1969)
3. Kohn. J.: Immunoelectroosmophoresis. In: C. A. Williams. M. W. Chase Methods in Immunology and Immunochemistry. Vol. 3, p. 277 (Academic Press. Inc.. New York. 1971)

4. Jordan, S. M.. and Morgan. E. H.: The development of selectivity of protein absorption from the intestine during suckling in the rat. Aust. J. Exp. Biol. Med. Sci.. 44: 465 (1968).

5. Laurell, C. B.: Quantitative estimation of proteins by electrophoresis in agarose gel containing antibodies. Anal. Biochem., 15: 45 (1966).

6. Lopata. E.: (learances of plasma proteins from pulmonary vascular beds of adult dogs and pups. Am. J. Physiol.. 21.3: 414 (1967).

7. Morris, B.. and Morris, R.: Quantitative assessment of the transmission of labeled protein by the proximal and distal regions of the small intestine of young rats. J. Physiol. (Lond.). 255: 619 (1976).

8 . Morris, B. and Morris, R. Macromolecular uptake and transport by the small intestine of the suckling rat. pp. 23-30 In: W. A. Hemmings: Antigen Absorption by the Gut. (University Park Press, Baltimore. MD, 1978)

9. Mott. J. C.: Haemorrhage as a test of the function of the cardiovascular system in rabbits of different ages. J. Physiol. (Lond.) 181: 728 (1965).

10. Peters. J. O.. and Van Slyke. D. D.: Special biochemical technique. In: Quantitative Clinical Chemistry. p. 65 (The Williams \& Wilkins Co., Baltimore. MD 1932).

I. Taylor, B.. Norman. A. P., Orgel, M. A.. Stoken, C. R.. Thomas, M. W.. and Scothill. J. F.: Transient IgA deficiency and pathogenesis of infantile atopy. Lancet, 2: 11 1 (1973).

12. Tolo, K., Brandtzaeg. P., and Jonsen. J.: Mucosal penetration of antigen in the presence or absence of serum-derived antibody. An in vitro study of rabbit oral and intestinal mucosa. Immunology, 33: 73 (1977).

13. Udall, J. N.. Fritze. L.. Sinclair, K. J., Pang, K. Walker. W. A. and Bloch, K. J. Binding of exogenous peptide fragments to native proteins: possible explanation for the overestimation of uptake of intact proteins from the gut. Fed. Proc (Abstract). 34: 1183 (1980)

14. Walker, W. A.: Antigen handling by the gut. Arch. Dis. Child.. 53: 527 (1978).

15. Williams, C. A., and Chase, M. W.: Two-dimensional immunoelectrophoresis for estimation of antigens in relative unit. In: C. A. Williams: Methods in Immunology and Immunochemistry. Vol. 3. p. 287 (Academic Press. Inc.. New York. $1971)$.

16. Wilzbach, K. E.: Tritium-labeling by exposure of organic compounds to tritium gas. J. Am. Chem. Soc., 79: 1013 (1957)

17. Wright. R. N.. and Rothberg. R. M.: The reactions of pepsin and pepsin-trypsin digestion products of bovine serum albumin with antisera from rabbits ingesting this protein. J. Immunol.. 107: 1410 (1971).

18. Zarrow. M. X.. Denenburg. V. H.. and Anderson. C. O.: Rabbit: Frequency of suckling in the pup. Science (Wash. D. C.). 150): 1835 (1965).

19. Dr. Udall was the recipient of a National Institutes of Health Research Training Fellowship in (linical Nutrition (T-32-AM-07070).

20. This study was presented in part at the annual meeting of the Society for Pediatric Research. May. 1980. Atlanta, Georgia.

21. Requests for reprints should be addressed to; J. N. Udall, M.D. Children`s Service (Pediatric Gastrointestinal and Nutrition Unit). Massachuselts General Hospital. Boston. MA 02114 (USA).

22. This research was supported in part by grants (HD-12437, AMDD-16269 and GM-217(x) f from the National Institutes of Health

23. Received for publication January 7. 1980.

24. Accepted for publication May 9, 1980. 